\title{
Intelligent automated system based on a fuzzy logic system for plant protection product control in orchards
}

\author{
P. Berk ${ }^{1 *}$, A. Belšak ${ }^{2}$, D. Stajnko ${ }^{1}$, M. Lakota ${ }^{1}$, N. Muškinja ${ }^{3}$, M. Hočevar $^{4}$, J. Rakun $^{1}$ \\ (1. Faculty of Agriculture and Life Sciences, University of Maribor, Pivola 10, 2311 Hoce, Slovenia; \\ 2. Faculty of Mechanical Engineering, University of Maribor, Smetanova 17, 2000 Maribor, Slovenia; \\ 3. Faculty of Electrical Engineering and Computer Science, University of Maribor, Smetanova 17, 2000 Maribor, Slovenia; \\ 4. Faculty of Mechanical Engineering, University of Ljubljana, Askerceva 6, 1000 Ljubljana, Slovenia)
}

\begin{abstract}
The spraying of plant protection product (PPP) in orchards is a very hazardous working procedure, owing to the spray drift caused by the uneven operation of conventional axial boom sprayers. This research describes an intelligent automated system for precise (PPP) distribution in real-time. It is based on an intelligent decision-making model using ultrasonic measurements of leaf area density under laboratory conditions, which serve to trigger electromagnetic valves (EMV) on the axial boom sprayer. A fuzzy logic algorithm was an integrated part of the intelligent system for controlling the PPP by generating the pulse width modulation signal and applying it through the EMV of the prototype boom sprayer. The results showed that by using an intelligent decision-making model, the same efficiency as with conventional methods could be achieved, but with reduced usage of plant protection products. Thus, the intelligent automated system used 4.8 times less spray mixture than the conventional one.
\end{abstract}

Keywords: plant protection product, boom sprayer, electromagnetic valve, fuzzy logic algorithm, tree canopy DOI: $10.25165 /$ j.ijabe.20191203.4476

Citation: Berk P, Belšak A, Stajnko D, Lakota M, Muškinja N, Hočevar M, et al. Intelligent automated system based on a fuzzy logic system for plant protection product control in orchards. Int J Agric \& Biol Eng, 2019; 12(3): 92-102.

\section{Introduction}

For decades, modern horticulture production has been using plant protection products (hereafter PPP) against disease, fungi, insects and weeds that need to be eliminated to ensure a good harvest. To treat plants, a range of spraying techniques and equipment can be used, such as sprayers, air blasters and foggers. These techniques are simple, robust, reliable and comparatively low cost in terms of purchase and operation. However, the spray plume generated by the fans is prone to spray drift; thus, there are large losses to the atmosphere. Ground saturation can occur, with a cumulative negative impact on the environment over time. It is impossible to eliminate these problems overnight by a complete return to the ecological method of cultivation, without the use of PPP.

The potential is limited for adapting the characteristics of the air stream generated by a fan sprayer to different tree canopies.

\section{Received date: 2018-11-01 Accepted date: 2019-02-18}

Biographies: A. Belšak, $\mathrm{PhD}$, Assistant Professor, research interests: mechanical engineering, mechanical construction and design, Email: ales.belsak@um.si; D. Stajnko, PhD, Full Professor, research interests: prediction of apple crops, irrigation systems, Email: denis.stajnko@um.si; M. Lakota, PhD, Associate Professor, research interests: precision agriculture, Email: miran.lakota@um.si; N. Muškinja, PhD, Assistant Professor, research interests: automation, control and intelligent systems, Email: nenad.muskinja @ um.si; M. Hočevar, PhD, Full Professor, research interests: intelligent sensing and manipulation, energy machines and devices, Email: marko.hocevar@ fs.uni-lj.si; J. Rakun, PhD, Assistant Professor, research interests: computer science and informatics, precision agriculture, Email: jurij.rakun@um.si;

*Corresponding author: Peter Berk, $\mathrm{PhD}$, Senior Lecturer, research interests: precision agriculture, measurement systems for tree canopy reconstruction, intelligent control systems for spray mixture flow rate control in orchards. Faculty of Agriculture and Life Sciences, University of Maribor, Slovenia. Tel: +386232090 55; Fax: +386261611 58, Email: peter.berk@um.si.
This can be achieved through selective and precise PPP application, among others methods. Because many growers still use traditional dose expression models, the dosage of PPP remains independent of the properties of each tree canopy in the orchard. The result is that potentially excessive dosages of PPP may be used in an orchard, given the distinct properties of individual trees in the orchard, such as volume, leaf area, height, age and growth stage.

For this reason, the capacity related to these sprayer features can be overcome by the use of systems for adjusting the applied dose of PPP according to the orchard structure (the tree row volume-TRV dosing concept); such systems are based on characterization of tree structures with the support of sensors, real-time signal processing technologies and real-time triggering of nozzles.

In more advanced PPP application controls, some researchers ${ }^{[1-16]}$ have begun to use precision control systems, which include a range of sensing systems. Based on information from the sensors, the sprayer's processing system detects the tree canopy in order to control I/O units, EMV and the dosage of PPP in different modes such as $\mathrm{ON} / \mathrm{OFF}^{[2,4,17]}$, discrete ${ }^{[18]}$ and continuous $^{[8,14,16,19,20]}$.

To ensure stable and sustainable fruit production, it is necessary to ensure a reduction in the harmful effects on the environment in which we live. The modern method of fruit production will be the only alternative in the future, where we will have to take into account environmental concerns. Therefore, we will need to apply smaller quantities of dangerous PPP while maintaining the same quality of crop protection in the orchard. This we can provide through continuous/proportional dosage rate control of PPP, according to the individual tree canopy in an $\operatorname{orchard}^{[8,16]}$.

The second important characteristic of sprayers is the position and orientation of the nozzles used for PPP application, which are 
fixed at a given height and only partly adapted to the non-linear shape of the tree canopy over the entire height. Osterman et al. $^{[15]}$ reported on the use of an adapted prototype sprayer with adjustable hydraulic manipulator arms. They used three manipulator arms, with installed aerodynamic airflow support and PPP nozzles featuring 8 degrees of freedom in a plane perpendicular to the row, with the intention of spraying targets perpendicular to the canopy contour at a selected distance. However, in the process of PPP application, it is not sufficient to measure the geometrical characteristics of each canopy tree alone. Moreover, it is necessary to selectively apply the appropriate amount of PPP to the selected canopy segment. In general, current state of the art sprayers are unable to deliver PPP precisely to selected targets; this means that a new generation of high precision sprayers is required.

The main goal of our research was to improve the PPP application process control by using advanced technologies (intelligent algorithms) and measurements of leaf area density as additional decision parameters and serve for more accurate control of sprayer liquid. The second objective of this research was to present a new approach to PPP application process control, by using hardware and software components, which would be implemented in the boom sprayer prototype under laboratory conditions.

\section{Materials and methods}

\subsection{Intelligent automated system}

The intelligent automated system was implemented on a conventional sprayer and tested under laboratory conditions, during which water was used for determining the most appropriate parameters for more precise control of spraying. The intelligent modular system (see Figure 1) consists of a conventional axial sprayer, measuring components for data acquisition (leaf area density) based on ultrasonic sensors, control components for EMV triggering in pulse width modulation (hereafter, PWM mode), Matlab R2015b/Simulink software, on which a decision-making model based on a fuzzy logic algorithm is running, and a mechanical trail to simulate the passing of the sprayer over the tree canopy. An automated system was used to apply an optimal quantity of water to the tree crowns, depending on their size and leaf area density. In the following sections, the individual components of the automated modular system are presented in detail.

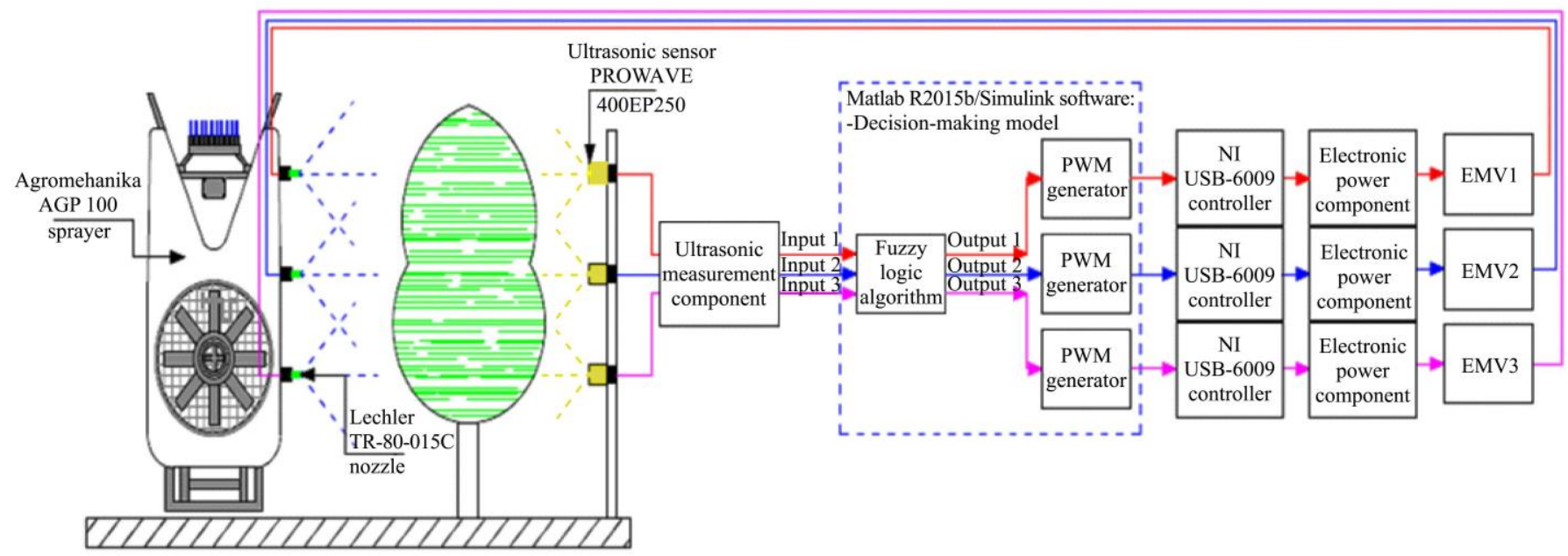

Figure 1 Structure of the intelligent automated modular system for the PPP process control application

\subsubsection{Electromagnetic valves}

Two-position (2/2) electromagnetic valves BDA-8W ED 100\% (StcValve, Palo Alto, USA) were installed on an axial boom sprayer (see Figure 2) to control the PPP process application. Typically, 2/2 normally closed (hereafter NC) EMV operate directly. Thus, when the electromagnetic coil of EMV is connected to a $12 \mathrm{~V}$ DC voltage power-supply, the EMV is opened.

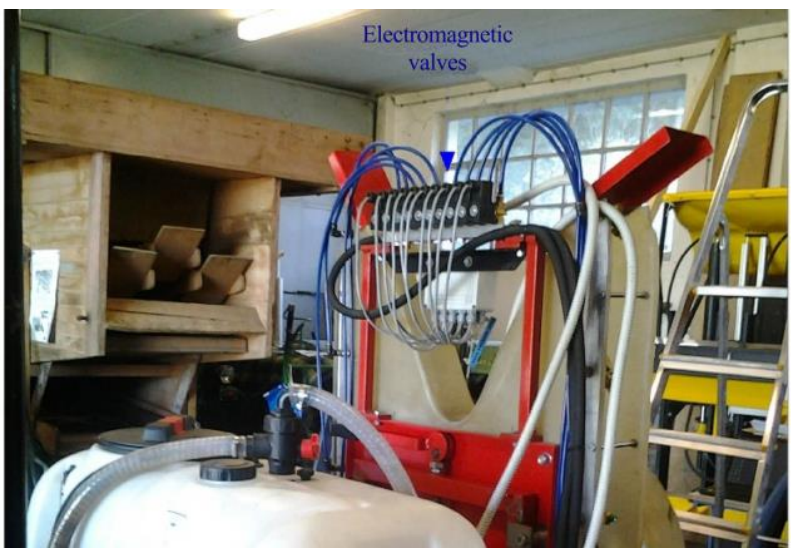

Figure $2 \quad 2 / 2 \mathrm{NC}$ electromagnetic valves mounted on a conventional sprayer
The valve normally operates at a maximum working pressure of 16 bar and is directly dependent on the nominal diameter of the valve seat and the electric power of the electromagnetic coil. In the laboratory experiment, the accurate EMV functioned at a frequency of $10 \mathrm{~Hz}$, which ensures the optimum deposit of PPP droplets (in the structure of the droplet stream, the majority of droplets were between $70-150 \mu \mathrm{m}$ in size $\left.{ }^{[22]}\right)$. More specific information about electromagnetic valves used in the experiment are shown in Table 1.

Table 1 Specifications of electromagnetic valves

\begin{tabular}{ccccc}
\hline Code: & Power: & Voltages: & ED: & Approvals: \\
\hline BDA08012CS & $8 \mathrm{~W}$ & V 12 DC & $100 \%$ & CE \\
Molding material: & Winding: & $\begin{array}{c}\text { Electrical } \\
\text { connections: }\end{array}$ & Coils: & $\begin{array}{c}\text { Max. allowable } \\
\text { pressure (PS): }\end{array}$ \\
$\begin{array}{c}\text { PA - Black } \\
\text { polyamide - } \\
\text { class F }\left(155^{\circ} \mathrm{C}\right)\end{array}$ & In class F & $\begin{array}{c}\text { EN 175301-803 } \\
\text { - Protection degree } \\
\text { DIN 40050 IP65 }\end{array}$ & $\begin{array}{l}30 \mathrm{~mm} \times \\
\varnothing 13 \mathrm{~mm}\end{array}$ & $16 \mathrm{bar}$ \\
\hline
\end{tabular}

\subsubsection{Ultrasonic measurement system}

An expanded version of a custom built ultrasonic measurement system described by Stajnko et al. ${ }^{[13]}$ was installed on a boom sprayer prototype. The measurement system consisted of a 
programmable ultrasonic unit, an embedded microcontroller and a mobile computer. The experimental work was performed under laboratory conditions, using an experimental composite rail track. The sensing tests and algorithm concepts were set up and then verified on the experimental composite rail track. First, the parameters of the programmable ultrasonic sensing system, such as reflected ultrasonic values, were derived by measuring an individual tree canopy. Then, by using these parameters as thresholds, a spraying experiment was performed. For the spraying experiment, a modified axial sprayer was used, while in operation it was evaluated by deposit measurement, using water-sensitive paper, which was then analysed using an automated vision system. In the following subsections, the design, operation and experimental procedure will be discussed in detail.

\subsubsection{Hardware design of the ultrasonic measurement system}

Figure 3 introduces the concept of interconnection between different parts of the system. On the left (see Figure 3), there are three ultrasonic sensors that are triggered (grey line) by the LPC1343 microcontroller. The sensors then transmit readings by using a RS-232 connection (blue lines), coupled by the AND gate to a MAX232 level shifter, which is connected to the UART (green line) of the microcontroller. The microcontroller reads the values from the sensors and packs them using a predefined protocol that is used with the mobile computer. The computer reads the packets, parses them and accordingly generates the output PWM signal for EMV.

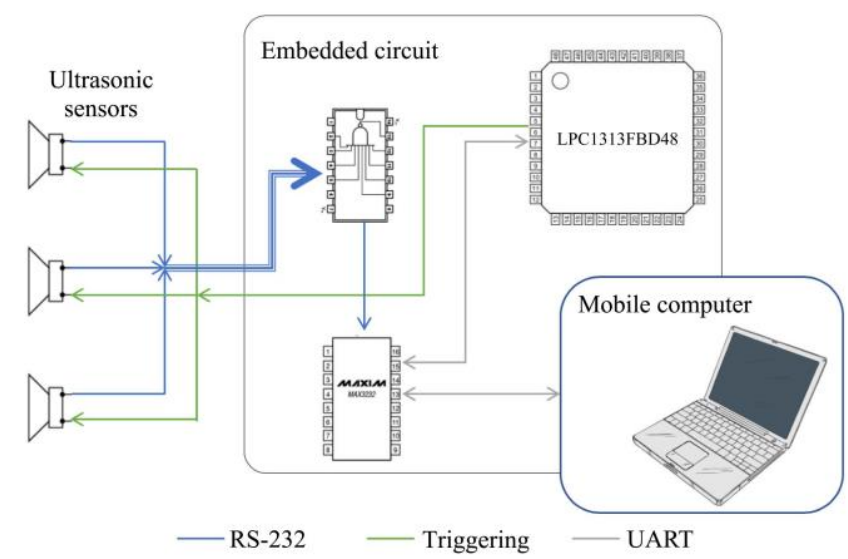

Figure 3 Connection of the major components of the embedded circuit with the ultrasonic sensors and mobile computer

2.1.2.2 Ultrasonic approach to measuring the leaf density of the tree canopy

In our work, we used an ultrasonic module designed around a CYPRESS CY8C29466-24SXI microcontroller that has $32 \mathrm{~KB}$ of Flash and $2 \mathrm{~KB}$ of Random Access Memory. The ultrasonic sensor with a basic electronic circuit includes a built-in ultrasonic transmitter, for which a PROWAVE 400EP250 transmitter was selected. The transmitter was connected to the microcontroller and uploaded with custom-written firmware developed by Stajnko et al. ${ }^{[13]}$ in $\mathrm{C}$ language and PSoC Designer. The ultrasonic sensor is controlled by triggering the " $\mathrm{Rx}$ " line microcontroller with pulses that have a width of $100 \mathrm{~ms}$. When the sensor is triggered, the transmitter generates an pulse of sound wave sent in the direction of the tree canopy. Each of the sensors sequentially generates a signal that is transmitted to a transceiver to produce an ultrasonic sound burst. The transceiver then waits to detect a reflected ultrasonic burst that contains information about leaf density in a time series evolution for reflected intensity. When the ultrasonic signal is reflected from the canopy, the receiving part of the transmitter receives the signal, which is then amplified by the FPGA electronic circuit of the microcontroller. The amplified signal is then time sampled and converted to a digital form. The sampled digitalized values correspond to the density of the tree canopies.

2.1.3 Automation controller

A programmable automation controller, NI USB-6009 (National Instruments, Austin, USA), was installed on the boom sprayer, because it is simple to use and offers the possibility of using more analog/digital inputs and outputs. Two physical analog output channels (analog outputs AO0 and AO1) were configured on the controller, which were used to activate the power semiconductor elements for controlling the EMV in the PWM mode, and one physical digital output channel (digital output P0.2) for actuating a semiconductor power element. The programming language of the NI USB-6009 was Matlab R2015b/Simulink (MathWorks, Natick, USA), which is a graphic language by means of which a decision-making model was written based on a fuzzy logic algorithm for the PPP process control.

\subsubsection{Spraying nozzles}

The boom sprayer was equipped with double membrane nozzles containing embedded ceramic mouthpieces TR-80015C (Lechler GmbH, Metzingen, Germany), which operate without air support. It has an $80^{\circ}$ spray angle, so it is suitable for depositing spray mixture droplets in vineyards and orchards. The nozzle working pressure for vineyards and orchards varies from 8 to 15 bar, whereas a 10 bar operating pressure was chosen for the experiments. Prior to the experiment, the characteristics of the nozzle flow rate were recorded in the laboratory to determine the nozzle flow rate $(\mathrm{L} / \mathrm{min})$, depending on the frequency of closing and opening the EMV.

\subsubsection{Composite testing track}

For controlling the PPP application under laboratory conditions, a composite testing track was designed, shown in Figure 4. The oval track platform with rails serves to driving a wheeled cart supporting a tree. Each cart was connected by a coupling rod to the chain, which moved between the two rails. The chain and chain box were driven by a 3-phase electric motor equipped with a frequency regulator (Commander SKB 3400075) to adjust the PTO shaft peripheral speed, used to simulate the sprayer prototype speed.

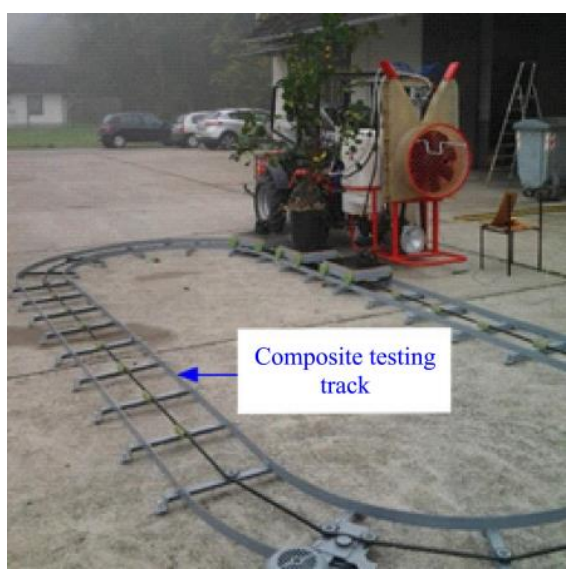

Figure 4 Experimental setup - composite testing track

\subsection{Laboratory prototype implementation}

The prototype boom sprayer consisted of an Agromehanika AGP 100 commercial sprayer (Agromehanika, Kranj, Slovenia), with nozzles originally mounted on both sides, but only 3 out of 5 from the right side were used in our experiment: the second 
(0.8 $\mathrm{m}$ from the ground), fourth $(1.33 \mathrm{~m})$ and fifth nozzles $(1.86 \mathrm{~m})$. Additionally, the prototype consists of an ultrasonic measurement system for tree canopy characterization (density of leaf area), an automated controller for executing the control algorithm, and actuators (EMV) for controlling the PPP application process in the PWM mode.

\subsubsection{Modification of the boom sprayer}

The hydraulic circuit of the boom sprayer includes all the commonly integrated parts, with the additional electronic components described in previous chapters, which enable the sprayer to operate in conventional as well as automated spraying mode (see Figure 5). The spraying amount was executed via a set of EMV and automated controller software. In the conventional process, all EMV were activated (opened), and subsequently the entire spraying boom was operating with all three nozzles at once. In contrast, in the automated process, the EMV were controlled with a PWM signal, which was generated by using an automated controller.

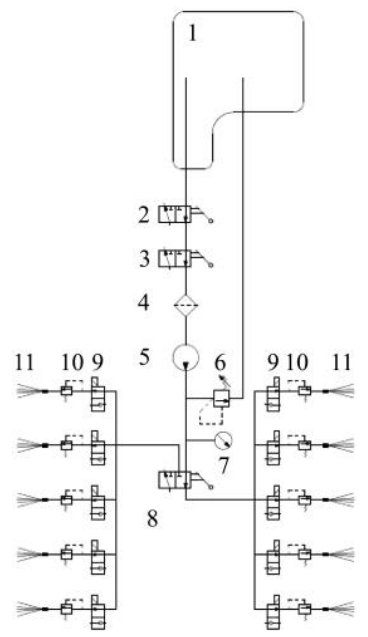

1. Tank 2, 3 and 8. Distributors 1, 2 and 3 4. Filter 5. Pump 6. Pressure and flow rate regulator 7. Pressure gauge 9. 2/2 electromagnetic valves 10. Anti-drift valves 11. LECHLER nozzles.

Figure 5 Diagram of the hydraulic circuit of the sprayer prototype

showing the implementation and the required components

\subsubsection{Spraying process}

The automated controller connected to the electronic power unit was guided by our own code written in the Matlab R2015b Package. In laboratory conditions, the spraying process prototype was monitored by a laptop on our own user interface, which enabled two application process modes (conventional and automated). In this way, we started and interrupted the process as well as measurement signal acquisition. The design of the code is shown as a block diagram in Figure 9.

The prototype boom sprayer provides the amount of PPP according to the active position of the EMV. In the conventional process mode, a constant amount of PPP was distributed in the tree canopy by sending a constant DC control signal to the EMV. Conversely, in the automated process mode, the PWM signal was sent to the EMV after it was defined by the inverse training function between the applied PWM signal and the leaf area density. These functions were experimentally determined under laboratory conditions in an open-loop controller mode.

In the case of the conventional process mode, the controller sent a $5 \mathrm{~V}$ DC control signal to three controller outputs, providing fully opened EMV at the same time, while in automated mode, the control signal was sent to the EMV together with the duty cycle of the PWM signal and depends on the leaf area density.
During the automated process mode, adjustment of the EMV through the PWM signal was tested whenever a tree canopy was detected at a specific distance from the sensors. Based on the intensity of the ultrasound corresponding to the density of the tree canopy, the amount of spray liquid was calculated for three different canopy heights according to the following equation:

$$
T P=\frac{1}{S R \cdot v}
$$

where, $T P$ is the time period for capturing ultrasonic echo signal intensity, $\mathrm{s} ; S R$ is the sampling resolution (samples $/ \mathrm{m}$ ), in our case, the resolution was 7 samples $/ \mathrm{m}^{[13]} ; v$ is the simulated travel speed of the prototype, $\mathrm{m} / \mathrm{s}$.

Activation of the EMV included the delay time in the leaf area density measurement processing, which depended on the distance between the ultrasonic measurement system, mounted on a steel console, and the nozzles on the sprayer boom. This means that the amount of liquid was estimated by the programming code and activated at the same height as the position of the nozzles. On the basis of multiple repetitions of these measurement processes, the best correlation was established among data acquisition, the liquid and the application process actuation. With the programming code, ultrasonic echo signals were normalized and converted into numerical values, which represented the input variables for the fuzzy logic algorithm; these have an impact on the output variables of the algorithm generating the signals for controlling the EMV and, consequently, on the amount of liquid through the nozzles.

\subsubsection{Decision-making model for controlling the PPP process}

The decision-making model for EMV control in the PWM mode is based on electronic measurement of leaf area density and a fuzzy logic algorithm, whereas the dose expression model per ha ground area is used to calculate the precise liquid dose expression rate through each single nozzle on a sprayer prototype. The output variable is called the variable coefficient $\left(\mathrm{V}_{\mathrm{C}}\right)$, and it enables more precise distribution of spray at three heights of the tree canopy. The variable coefficient was determined from the group of empirical rules provided in several experiments performed by Berk et al. ${ }^{[21]}$. To build the fuzzy logic algorithm, a 'Fuzzy inference system' (hereinafter FIS) toolbox from Matlab R2015b software package was applied.

The main task of the decision-making model was to include density measurements of the canopy for controlling the amount of spray and deposit on the leaf area of the tree canopy, more precisely at a constant sprayer speed and constant distance. The measurements from the ultrasonic system served to generate accurate values for controlling the opening time of the EMV.

It is very difficult to describe precisely the model for spraying application control mathematically, because the process is both non-linear and dynamic in nature. Giles ${ }^{[22]}$ found that every change occurring in the natural environment, such as canopy shape obstacles or varying speed of the tractor pulling the sprayer, has an effect on the system; thus, the fuzzy logic algorithm was chosen as the most appropriate tool, while the rules and membership functions for input variables were labelled as Sensor 1, Sensor 2 and Sensor 3, representing three heights of the ultrasound measurement system on one side, and El-mag-V1, El-mag-V2 and El-mag-V3 as output parameters representing variable coefficients, on the other side.

The optimization procedure for the decision-making model based on the fuzzy logic algorithm started with the fuzzification, performed by Mamdani et al. ${ }^{[23]}$, of three input and three output variables. From all language variables, a trapezoid shaped 
membership function proved the most suitable in our experiments and was used with the thresholds for closing and opening the EMV shown in Figures 6 and 7. There, trapezoid-shaped membership functions are represented for the input/output variables 'Sensor 1' and 'E-mag-V1'. The membership functions were defined separately in the interval between $[0,600]$, as follows:

- the input of Sensor 1 and output for El-mag-V1 variable: [0 0150 200; 150250350 450; 400450600 600],

- the input of Sensor 2 and output for El-mag-V2 variable: [0 0150 200; $150250350450 ; 400450600$ 600] and

- the input of Sensor 3 and output for El-mag-V3 variable: [0 0150 200; 150250350 450; 400450600 600].

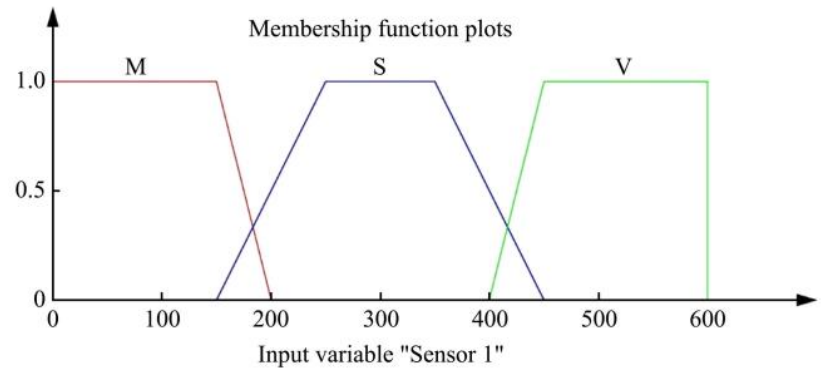

Figure 6 Membership functions for input variable - Sensor 1

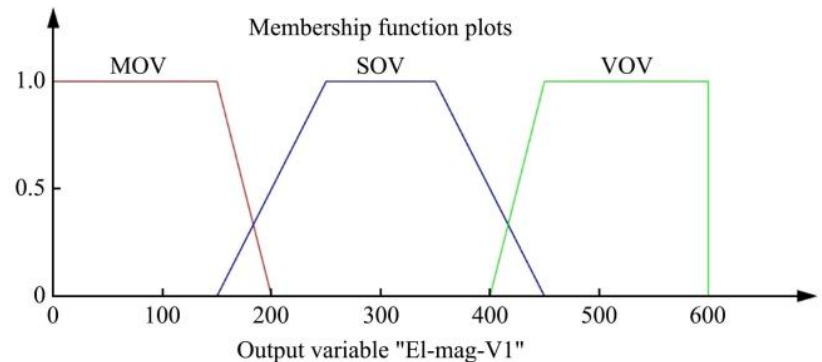

Figure 7 Membership functions for output language variable El-mag-V1

To improve the model for controlling the application process, additional language variables were defined (see Table 2), which made changes in the shape of membership functions possible and added new rules to the fuzzy logic algorithm. When adding new language variables, we included the inclination gradient in the form of numeric values corresponding to the reflected ultrasound signal bouncing back from the tree canopy.

Table 2 Input and output language variables with descriptions

\begin{tabular}{cc}
\hline Language variables & Description of language variables \\
\hline M & Low \\
S & Middle \\
V & High \\
MOV & Partly open valve \\
SOV & Half open valve \\
VOV & Fully open valve \\
\hline
\end{tabular}

The referential values of different input language variables represent normalised values of the reflected ultrasound signal at three different tree canopy heights. On the other side, the values of different output language variables represent the variable coefficients with which the automated system periodically set the minimum and maximum width of the pulse (duty cycle) for controlling the EMV valves.

After the fuzzification procedure of the three different input and output variables, the procedure interference representing the decision procedure was continued. The interference was achieved by employing the rules for EMV control in PWM mode, as shown in Table 3. The total number of rules is defined by Equation (2):

$$
N=p^{m}=3^{3}=27
$$

where, $m$ represents the number of input language variables; $p$ is the number of language variable levels.

Table 3 Control rules for EMV control

\begin{tabular}{|c|c|c|c|c|c|c|}
\hline \multirow{2}{*}{ Rules } & \multicolumn{3}{|c|}{ Input variables } & \multicolumn{3}{|c|}{ Output variables } \\
\hline & Sensor 1 & Sensor 2 & Sensor 3 & El-mag-V1 & El-mag-V2 & El-mag-V3 \\
\hline 1 & M & M & M & MOV & MOV & MOV \\
\hline 2 & $\mathrm{~S}$ & $\mathrm{~S}$ & $\mathrm{~S}$ & SOV & SOV & SOV \\
\hline 3 & $\mathrm{~V}$ & $\mathrm{~V}$ & $\mathrm{~V}$ & VOV & VOV & VOV \\
\hline 4 & M & M & $\mathrm{S}$ & MOV & MOV & SOV \\
\hline 5 & M & M & V & MOV & SOV & VOV \\
\hline 6 & M & $\mathrm{S}$ & M & MOV & SOV & SOV \\
\hline 7 & M & $\mathrm{S}$ & $\mathrm{S}$ & MOV & SOV & SOV \\
\hline 8 & M & $\mathrm{S}$ & V & MOV & SOV & VOV \\
\hline 9 & M & $\mathrm{V}$ & $\mathrm{M}$ & SOV & VOV & SOV \\
\hline 10 & M & $\mathrm{V}$ & $\mathrm{S}$ & SOV & VOV & SOV \\
\hline 11 & M & $\mathrm{V}$ & $\mathrm{V}$ & SOV & VOV & VOV \\
\hline 12 & $\mathrm{~S}$ & M & M & SOV & MOV & MOV \\
\hline 13 & $\mathrm{~S}$ & M & $\mathrm{S}$ & SOV & MOV & SOV \\
\hline 14 & $\mathrm{~S}$ & M & $\mathrm{V}$ & SOV & MOV & VOV \\
\hline 15 & $\mathrm{~S}$ & $\mathrm{~S}$ & M & SOV & SOV & SOV \\
\hline 16 & $\mathrm{~S}$ & $\mathrm{~S}$ & $\mathrm{~V}$ & SOV & SOV & VOV \\
\hline 17 & $\mathrm{~S}$ & $\mathrm{~V}$ & $\mathrm{M}$ & SOV & VOV & SOV \\
\hline 18 & $\mathrm{~S}$ & $\mathrm{~V}$ & $\mathrm{~S}$ & SOV & VOV & SOV \\
\hline 19 & $\mathrm{~S}$ & $\mathrm{~V}$ & $\mathrm{~V}$ & SOV & VOV & VOV \\
\hline 20 & V & M & M & VOV & SOV & MOV \\
\hline 21 & $\mathrm{~V}$ & M & $\mathrm{S}$ & VOV & SOV & SOV \\
\hline 22 & $\mathrm{~V}$ & M & $\mathrm{V}$ & VOV & SOV & VOV \\
\hline 23 & V & $\mathrm{S}$ & M & VOV & SOV & SOV \\
\hline 24 & V & $\mathrm{S}$ & $\mathrm{S}$ & VOV & SOV & SOV \\
\hline 25 & V & $S$ & V & VOV & SOV & VOV \\
\hline 26 & V & V & M & VOV & VOV & SOV \\
\hline 27 & V & V & $\mathrm{S}$ & VOV & VOV & SOV \\
\hline
\end{tabular}

Procedure inference in the fuzzy logic algorithm was defined with the help of "IF-THEN" rules ${ }^{[23,24]}$. These reflected the relation between the leaf area density and the amount of sprayer liquid through a single EMV. By setting rules, EMV can be controlled according to the variable coefficient. Therefore, in our case, a sharp value (variable coefficient) was determined representing the output of the fuzzy logic algorithm for each EMV separately.

In the last stage of the fuzzy logic algorithm - defuzzification a centroid method ${ }^{[24,25]}$ was selected for variable coefficient calculation for controlling EMV. With the variable coefficient, the duty cycle of the PWM signal was controlled in a range from $0 \%$ to $100 \%$ (relative value from 0 to 1 ), thus regulating liquid amount through the EMV. The liquid amount through each nozzle on a sprayer prototype was determined according to Equation (3):

$$
q=V_{C} \cdot\left(\frac{N F R \cdot 600}{a \cdot v}\right)
$$

where, $q$ is the amount to be sprayed at a particular tree canopy height, $\mathrm{L} / \mathrm{min}$; NFR is the nozzle flow rate, $\mathrm{L} / \mathrm{min} ; 600$ is the factor needed to convert different units; $a$ is a working width, $\mathrm{m}$. 
Because only one side of the prototype sprayer was operational in the experiment at a working width of $0.3 \mathrm{~m} ; v$ is the simulated travel speed of the sprayer, $\mathrm{km} / \mathrm{h} ; V_{C}$ is the variable coefficient produced by fuzzy logic algorithm (relative values from 0 to 1 ).

The entire fuzzy logic algorithm was optimized by adjusting the stability, robustness, quality and response of the membership function language variable values, their shape and rules. The fuzzy logic algorithm was included in the final decision-making model, in which dynamic properties were taken into account. The model for synthesizing the process of liquid application was built using the Matlab R2015b/Simulink environment, depicted in
Figure 8.

Based on the fuzzy logic algorithm, a real-time liquid application process was built (Figure 9), consisting of many separate blocks, subsystems and hardware units. Their task is to capture data from the ultrasonic measurement system created by Stajnko et al. ${ }^{[13]}$ through the RS-232 interface, parse it into useful information, trigger the EMV with a delay, generate the PWM signal, reset the values and convert the data types. The model also includes drivers for the NI-USB 6009 control component that was used to set the analog/digital outputs and generate the PWM signal for controlling the EMV and the amount of liquid.

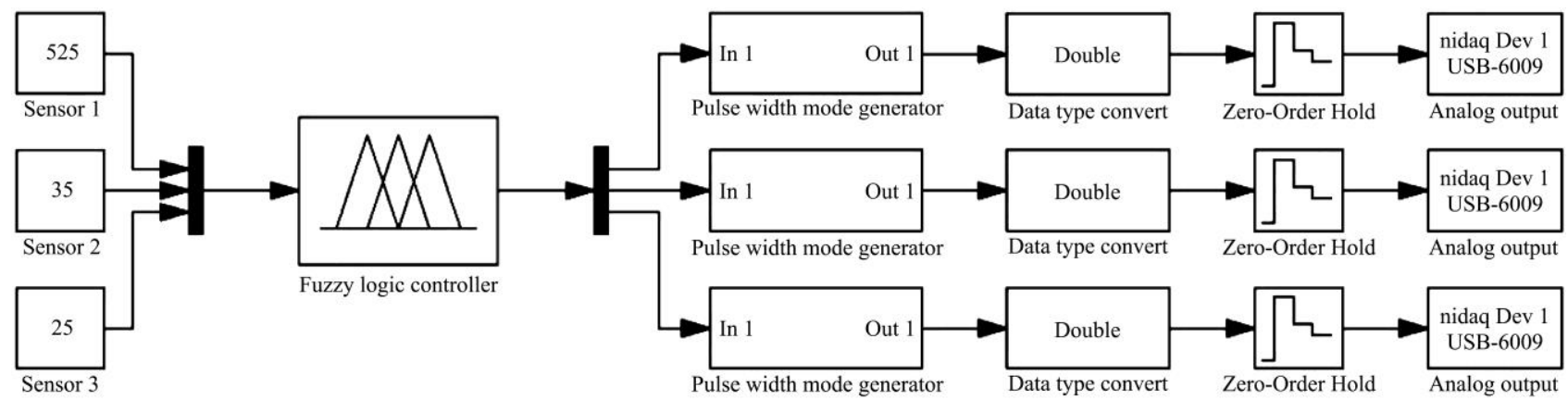

Figure 8 Block diagram of a fuzzy logic algorithm developed in Matlab R2015b/Simulink

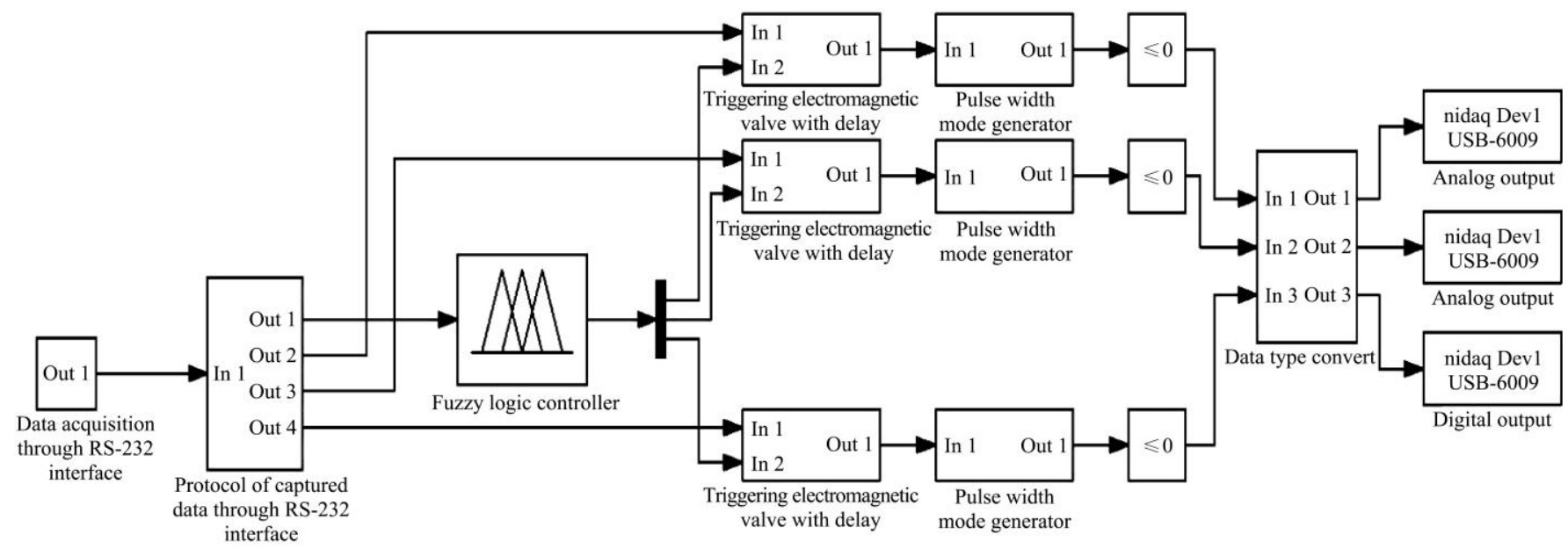

Figure 9 Block diagram algorithm for real-time liquid application process control developed in Matlab R2015b/Simulink

\subsubsection{Canopy characterization}

For tree canopy characterization, an upgraded ultrasonic measuring system described by Stajnko et al. ${ }^{[13]}$ was used. The sensors were positioned in three rows with three sensors. The middle sensors generated the ultrasound, while the right and left sensors measured the reflected ultrasound, Figure 10. By using

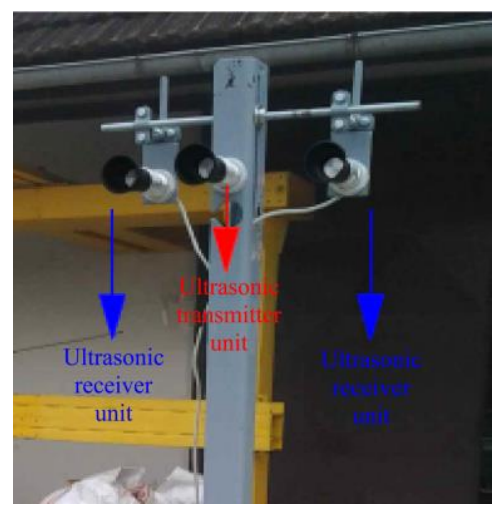

Figure 10 Formation of ultrasonic sensors - two receiving and one transmitting sensor unit for each canopy height multiple ultrasonic sensors, the canopy was split into three different segments according to the height of the sensors, which enabled the spraying application on one half of the tree canopy facing the operational side of the sprayer. The leaf area density at three canopy heights was estimated from the readings of the ultrasonic sensors (PROWAVE 400EP250, Unitronic Gmbh, Düsseldorf, Germany) every $0.15 \mathrm{~cm}$ along the testing track. Thus, a sampling resolution (SR) was 7 samples per meter. Leaf area density measurements at three canopy heights were the inputs to the decision-making model for controlling the automated spraying mode and were used to determine the spray amount according to the leaf area density at three different heights of the tree canopy.

\subsection{Laboratory experiments}

2.3.1 Synchronization time for the spraying process

One of the most important factors in the real-time spraying process is the synchronization time, which depends on the frequency of triggering and acquisition of the ultrasonic signal. Normally, measurement of the leaf area density starts when one of the ultrasonic sensors detects the first ultrasonic echo signal and its values exceed a minimum threshold value for leaf area density. The measuring process was terminated when the value of the echo 
signal was below the minimum threshold value. "Software time" between the "On" and "Off" measuring process was used in calculating the leaf density. By processing the input data on the tree canopy, the average value of leaf density was estimated, which was necessary to control the time delay for EMV actuation. This time was calculated by the software program and depended on the relative position between the tree canopy and the nozzles, as well as driving the speed of the prototype sprayer, which was set at $1 \mathrm{~m} / \mathrm{s}$. As this is a real-time system it is necessary to asses the time delay caused by ever electronic component separately and in total. The main processing unit is the HP Compaq 6830s laptop that processes the data at $50 \mathrm{~Hz}$, with each iteration taking around $20 \mathrm{~ms}$. The second component is the electronic circuit that recorded the readings and triggered the electro-magnetic valves and communicated with the laptop. The embedded microcontroller runs at $72 \mathrm{MHz}$ and uses a 57600 bps serial communication. Each iteration of the readings is first received from each of the 6 sensors taking 7 bytes each and this data is then pass on to the laptop in 42 bytes long packets. This means the whole processing and communication on the microcontroller for one iteration takes around $12 \mathrm{~ms}$. Measuring part of the ultrasonic sensor was timed to $25 \mathrm{~ms}$. The last part are the electro-magnetic valves that have the highest delay and reach around 20-40 ms according to the manufacturer. So the processing speed of the electronic circuit was therefore evaluated to be around $80-100 \mathrm{~ms}$ per iteration.

\subsubsection{Sprayer liquid amount control}

For accurate sprayer amount control, it was necessary to determine the frequency range of the generated PWM signal and the maximum frequency at which the EMV can normally operate. In an empirical test, the maximum frequency of $10 \mathrm{~Hz}$ was estimated. Beyond this range, the opening and closing of the EMV is not complete, owing to high negative voltage. The EMV actuation was tested at a working pressure of 10 bar and four different scenarios: (1) fully opened EMV, (2) the period of the PWM signal for EMV control set at $1 \mathrm{~Hz}$, (3) the period of the PWM signal for EMV control set at $5 \mathrm{~Hz}$, and (4) the period of the PWM signal for EMV control set at $10 \mathrm{~Hz}$. The influence of different PWM signals on the control of spraying amount through EMV was estimated. The different generated shapes (duty cycles) of the PWM signals serve to control the EMV and consequently the liquid amount at the widest range. Trough the decision-making model, a duty cycle signal was generated, which is based on a fuzzy logic algorithm and can be continuously set to an open time of EMV from $0 \%$ to $100 \%$ and affects the spray liquid amount control.

The results of EMV testing were further applied on a LECHLER TR80015C nozzle to control the accuracy and quantity of the spraying flow rate at different frequencies, which is necessary to distribute the droplets evenly over the leaf area.

Finally, the liquid amount was calculated at three different canopy heights according to Equation (4):

$$
Q_{V}=\sum_{i=1}^{n=3} V_{C i} \cdot\left(\frac{N F R}{60 \cdot v \cdot S R}\right)
$$

where, $Q_{V}$ is the sprayed water volume, L/sample; $V_{C i}$ is the variable coefficient calculated by the fuzzy logic algorithm for three different canopy heights (relative volume from 0 to 1 ); NFR is the nozzle flow rate, $\mathrm{L} / \mathrm{min} ; v$ is the simulated travel speed of the sprayer, $\mathrm{m} / \mathrm{s} ; S R$ is the sampling resolution, samples $/ \mathrm{m}$.

\subsection{Experimental implementation}

Before experimental implementation, the intelligent automated system was calibrated by placing ultrasound sensors $0.3 \mathrm{~m}$ from the tree canopy, which is the optimal distance for leaf area density evaluation, as established by Berk et al. ${ }^{[26]}$, where four modes of the spraying process were tested. In conventional mode, the EMV were fully open, while in the three decision-making automated models based on the fuzzy logic algorithm, the duty cycle fraction was adjusted by the period of the PWM signal at $1 \mathrm{~Hz}, 5 \mathrm{~Hz}$ and $10 \mathrm{~Hz}$. To assess the number of droplets, coverage and droplet size of the conventional and automated modes water sensitive paper (hereafter WSP) was used. The WSP was positioned on the tree canopy at the $0.8 \mathrm{~m}$ (position P1 and P2), $1.33 \mathrm{~m}$ (position P3 and P4) and $1.86 \mathrm{~m}$ height (position P5 and P6) for each of the tests separately, as shown in Figure 11. By placing more than one WSP on each tree canopy, we increased the sampling resolution for droplet distribution at each height. Then we ran the track with the wheeled cart and the tree to pass by the intelligent automated system. After each pass by the cart, the track was stopped so the WSP could dry out, and we removed them from the tree. Each of the WSP was placed separately in a labelled plastic bag and left in cool storage awaiting analysis in the laboratory. Later, the WSP was analysed using the Optomax Image Analyzer (Optomax, Hollis City, NH USA) into formatted computer spreadsheets (Microsoft Excel), prior to statistical analysis of variance (2 treatments $\times$ 5 repetitions $\times 12$ locations) using the Statgraphics Statistics Package Program.

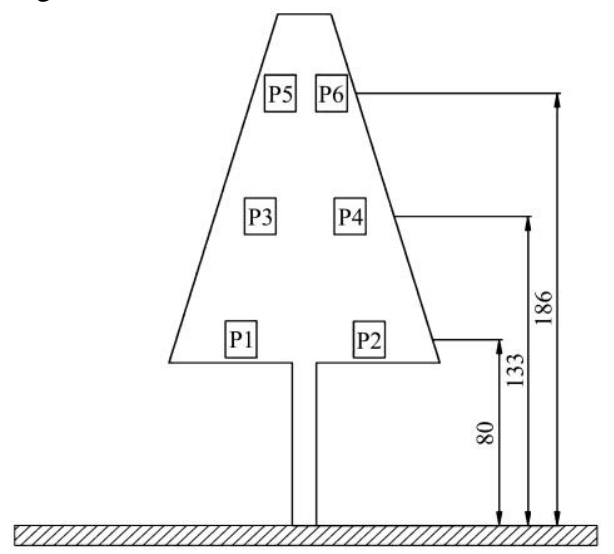

Figure 11 Position of WSP (in $\mathrm{cm}$ ) over the tree

The intelligent automated system was tested by the "Agricultural Engineering Department" at the Agricultural Institute of Slovenia. All tests were performed using a $2.2 \mathrm{~m}$ high apple tree canopy at phonological stage BBCH 69, Figure 12.

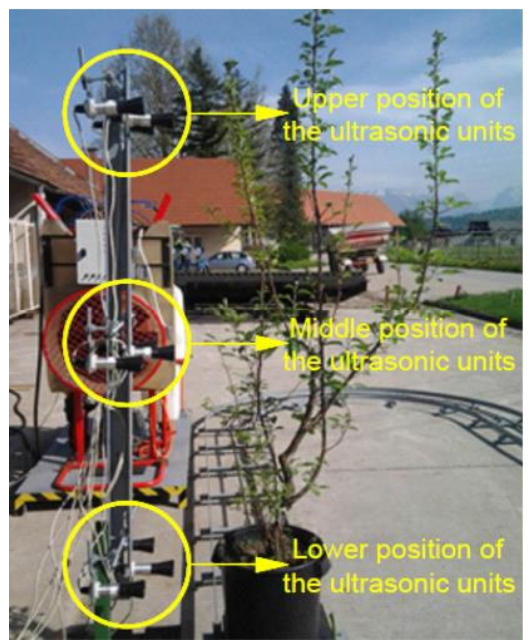

Figure 12 Laboratory experimental setup used to test the liquid application process 


\section{Results and discussion}

\subsection{Laboratory experiment trials}

\subsubsection{Laboratory testing of EMV and nozzle}

On the basis of the laboratory calibration, a range of frequency for the periodic opening/closing of EMV was determined in the range from $1 \mathrm{~Hz}$ to $19.23 \mathrm{~Hz}$, which ensures accurate control of EMV. Figure 13 shows the periodic opening/closing of EMV at

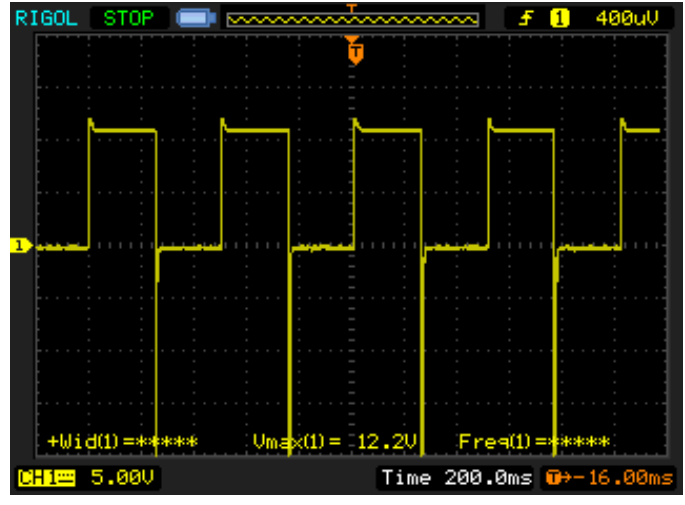

a. $1.92 \mathrm{~Hz}$

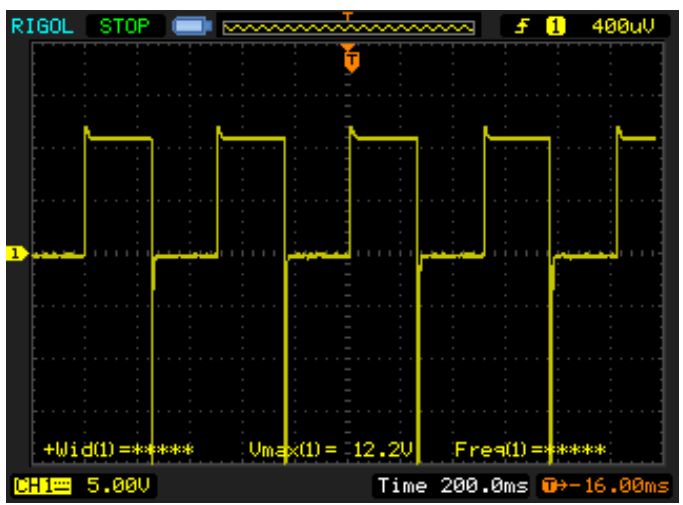

c. $10 \mathrm{~Hz}$ different frequencies for controlling the spray flow by using a digital oscilloscope RIGOL DS1102CA (RIGOL TECHNOLOGIES EU, Puchheim, Germany). As seen, rather large negative overvoltage was detected (the green circle in Figure 13a), which is limited by a protective diode. At a frequency of 19.23 Hz, the precision of the opening/closing of EMV can no longer be guaranteed, since it leads to excessive delay in closing the EMV-Figure 13d.

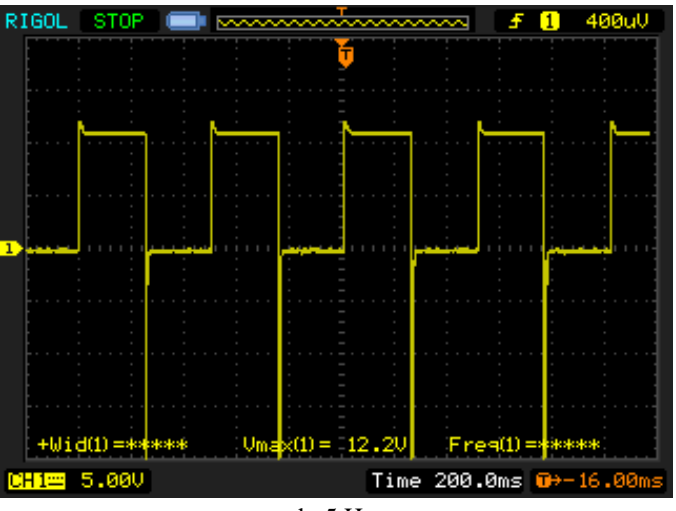

b. $5 \mathrm{~Hz}$

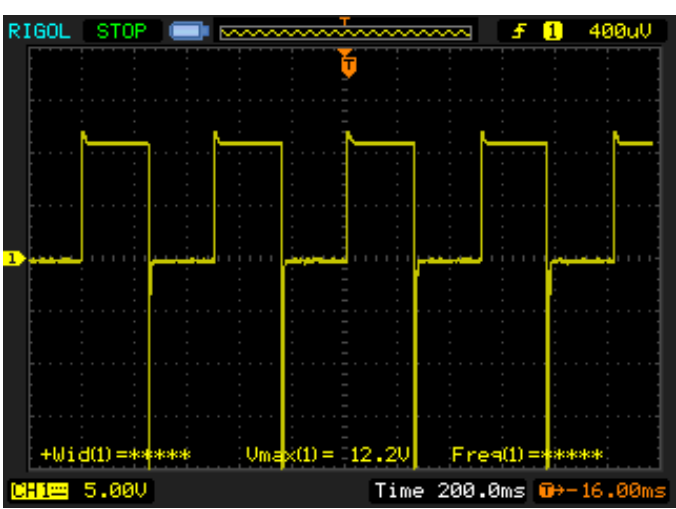

d. $19.23 \mathrm{~Hz}$

Figure 13 PWM signal for opening/closing of EMV at a frequency of $1.92 \mathrm{~Hz}, 5 \mathrm{~Hz}, 10 \mathrm{~Hz}$ and $19.23 \mathrm{~Hz}$, at $12 \mathrm{~V}$ DC voltage magnitude

Figure 14 shows the influence of different frequencies on the spray flow rate of the LECHLER TR8001C nozzle, and yields a practically linear correlation over the whole spectrum of frequencies. The task of the nozzles is to spray a liquid stream with a specific spectrum of droplets that are directed towards the leaf area. Spray quality is assessed by the deposition of droplets on a leaf area, thus indicating the quality of nozzle operation. We believe that using the linear relationship between the two variables (frequency, nozzle flow rate) enabled precise continuous control of spraying flow and deposition of droplets in the automated mode.

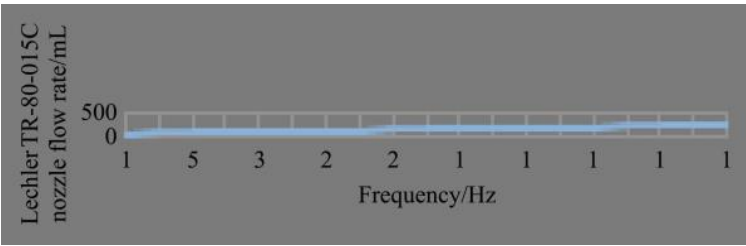

Figure 14 Frequency characteristics of the nozzle flow rate

3.1.2 Laboratory field validation trials of the ultrasonic measurement system

The method developed by Berk et al. ${ }^{[26]}$ was implemented to analyse the influence of the ultrasonic measurements on the distance. This method returns the highest peak density for the two left and right ultrasonic receiver units shown in Figure 10. The method can simultaneously calculate the average peak density value for the two left and right ultrasonic receiver units. The highest density peak readings and average values of the signal reflected from the tree canopy are shown in Figure 15, in which a ten-fold repetition of the tree canopy passed through the ultrasonic measurement system to calibrate the system. The results were normalized into number values.

\subsubsection{Variable-rate decision-making model}

Before starting the practical experiment with the prototype sprayer, the variable-rate decision-making model was optimized according to the three partial procedures already explained in detail in section 2.2.3. As shown in Figure 16, differences in the reflected signal affect the generation of different PWM signals by active control rules. The Figures $16(\mathrm{a}, \mathrm{b}$ and $\mathrm{c}$ ) demonstrate the principle of decision-making model operation: namely, in the case of high value intensity of the echo signal reflected from the tree canopy sent to the decision-making model input, the first model output generated a PWM signal with an $85.5 \%$ duty cycle fraction of one time period. In the case of lower values for the intensity of the reflected echo signal sent to the second and third model input, the second model output yielded a PWM signal with a 50\% and the third output a PWM signal with a $14.43 \%$ duty cycle fraction of one time period. On the $50 \%$ duty cycle fraction by a relatively low intensity value of the reflected signal influence the active control rules on the second model output. 

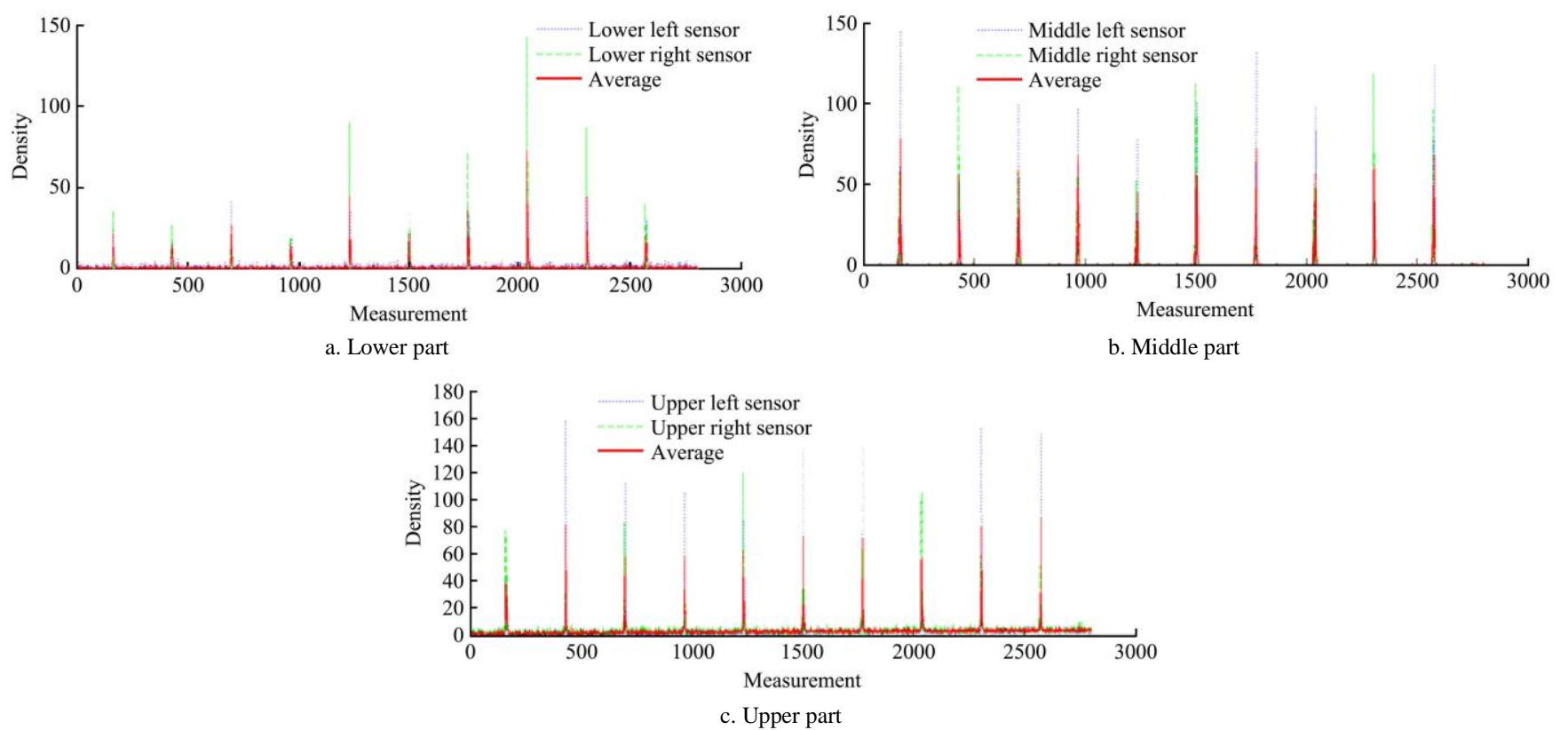

Figure 15 Density value of the reflected signal at the different parts of the tree canopy
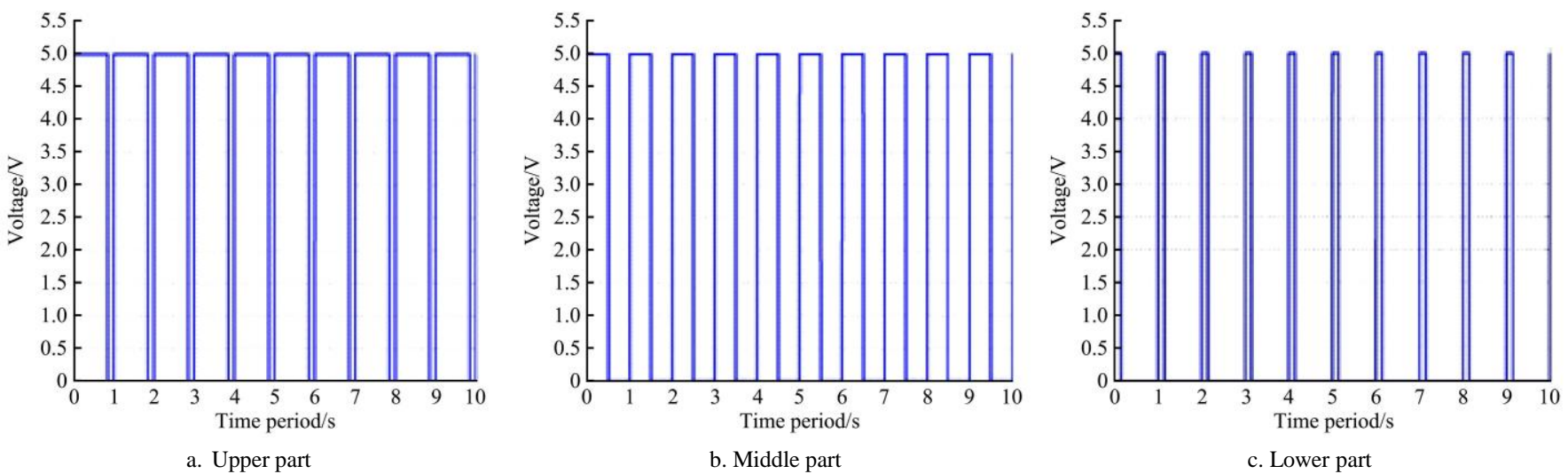

Figure 16 Optimized form of PWM signal at the different parts of the tree canopy

\subsection{Laboratory field validation trials}

To indicate a reduction rate of spray volume WSP papers were used. WSP analysis were performed postpone in the laboratory using an Optomax Image Analyser for estimating the number of PPP droplets and the percentage of coverage on WSP surface. The results of automated mode are represented in Figures 17 (a-f), and in conventional mode in Figures 17 (g-l). Figures 17 (a-f) show the optimal coverage and the number of PPP droplets, which was obtained in the third test of automated mode (see Figures 18 and 19).

The maximum spray mixture droplet coverage was estimated on average in conventional spraying, whereby within this mode, the maximum coverage $(72.69 \%)$ was on the lower part of the canopy (P1) and the minimum coverage on the top (P6) was $17.19 \%$. Figure 18 summarizes the number of droplets on the WSP for each of the tests according to its position on the tree. The most uniform distribution of droplets was detected in test three (automated $10 \mathrm{~Hz}$ ); $103 \mathrm{drop} / \mathrm{cm}^{2}$ - position P1, $148 \mathrm{drop} / \mathrm{cm}^{2}$ - position P2, $78 \mathrm{drop} / \mathrm{cm}^{2}$ - position P3, $69 \mathrm{drop} / \mathrm{cm}^{2}$ - position $\mathrm{P} 4,134 \mathrm{drop} / \mathrm{cm}^{2}$ - position P5 and $91 \mathrm{drop} / \mathrm{cm}^{2}$ - position P6. All these values agreed with the propositions of the Syngenta producer ${ }^{[27]}$, saying that between 20 $70 \mathrm{drop} / \mathrm{cm}^{2}$ are required to successfully treat the plant with PPP. The droplet structure of the spray mixture was expressed in $\mu \mathrm{m}$, where in the third test the most suitable result was, that the numeric median diameter (hereafter NMD) was $50.16 \mu \mathrm{m}$, and the volume median diameter (hereafter VMD) was $151.56 \mu \mathrm{m}$, measured by the Optomax Image Analyzer. Similar results were found by Escola et al. ${ }^{[16]}$, who calculated a value for the NMD parameter of $54.16 \mu \mathrm{m}$ and for VMD parameter of $156.20 \mu \mathrm{m}$ at a pressure of 8 bar.

Figure 19 shows coverage on WSP for all four test cases. As seen, the maximum coverage was estimated on average in conventional spraying: in this mode, maximum coverage $(72.69 \%)$ was estimated on the lower part of the canopy (P1) and minimum coverage on the top (P6) position, 17.19\%. Conversely, the minimum coverage was estimated on average in the fuzzy logic spraying at $1 \mathrm{~Hz} \mathrm{PWM}$, ranging from $1.00 \%$ at the $\mathrm{P} 4$ position, to $5.30 \%$ at the P5 position, which however, was not enough for accurate protection against diseases and pests. For this reason, fuzzy logic spraying at $10 \mathrm{~Hz}$ PWM with an average coverage of 9.59\% represents the most even distribution of PPP over the tree canopy, ranging from $15.02 \%$ (P2 position) to $4.49 \%$ (P4).

The amount of liquid in the experiment for successful treatment of the tree canopy was in the range recommended by the Syngenta producer $^{[27]}$. For this reason, the use of a decision-making model based on a fuzzy logic algorithm proved to be a significant improvement to spraying over the conventional approach, because it allowed sufficient coverage to the tree canopy with a lower flow rate of the spray mixture.

If the leaf area density of the canopy was low, the EMV would be opened for only a minimum of the duty cycle of the PWM signal, 
thus reducing the spray mixture flow rate. A lower PPP amount was distributed on the tree canopy, and less drift was emitted into the environment. If the canopy were denser, the EMV would have to be opened longer during the duty cycle of the PWM signal, and thus more PPP would be used to achieve the same result, but again with minimum impact on the environment.
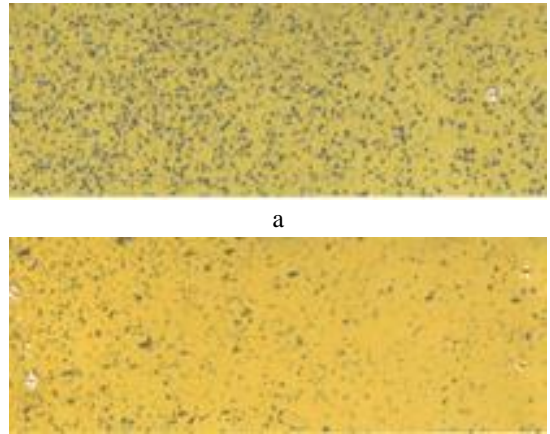

d
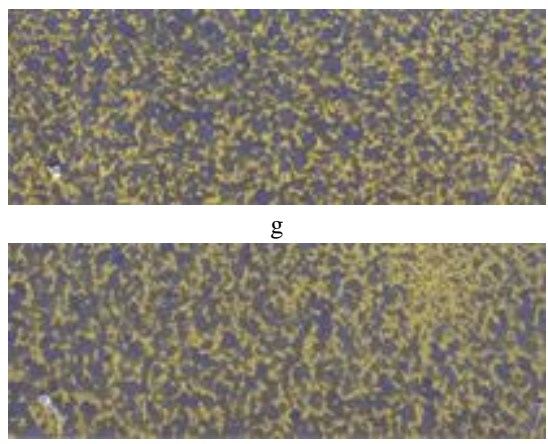
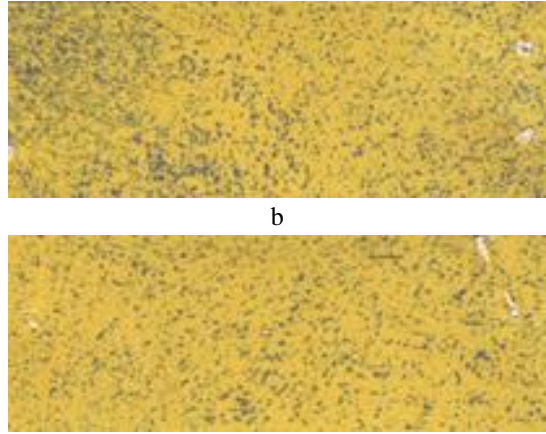

$\mathrm{e}$

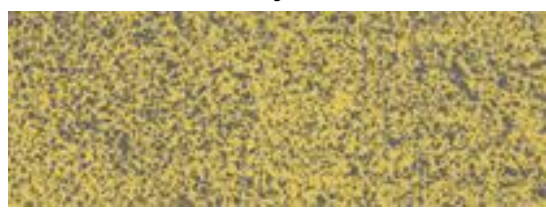

$\mathrm{h}$

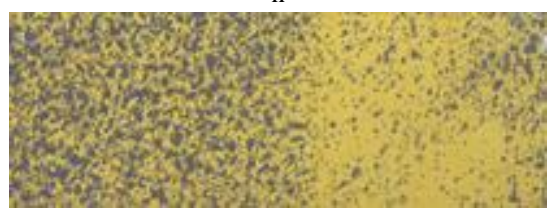

$\mathrm{k}$
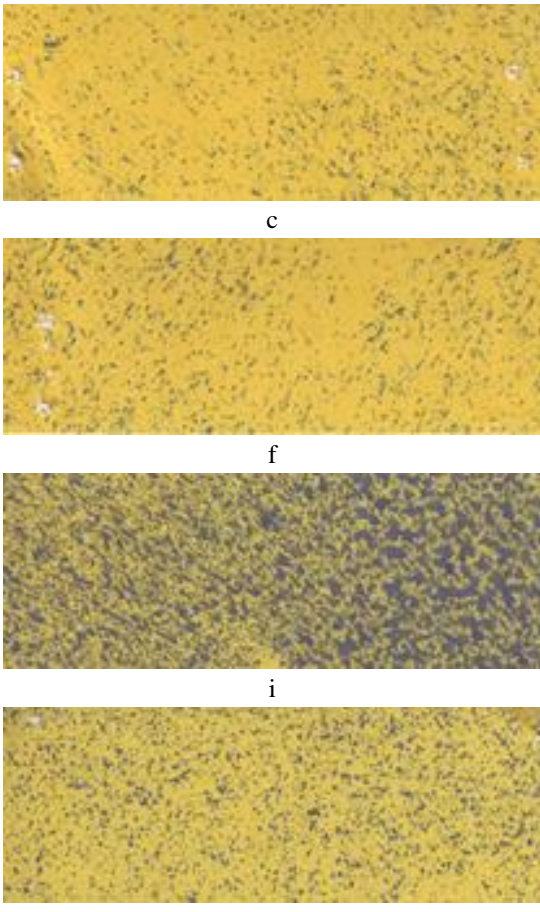

Figure 17 PPP droplets coverage on the WSP at tree canopy position P1-P6 (third test-automated mode (a -f) and fourth test-conventional mode $(\mathrm{g}-1)$

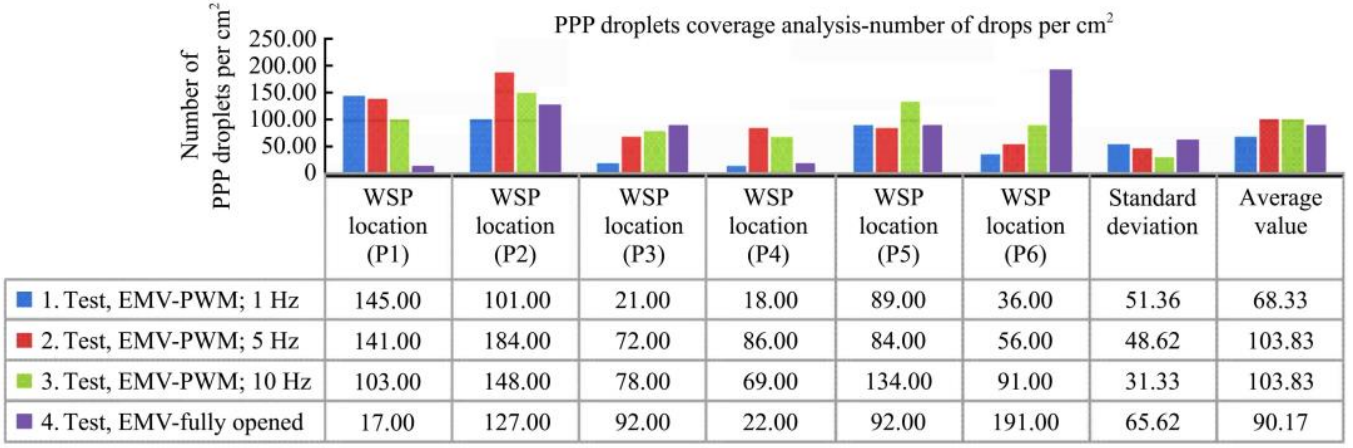

Figure 18 Droplet coverage for all four tests - at 1,5,10 Hz and fully opened EMV and six different positions

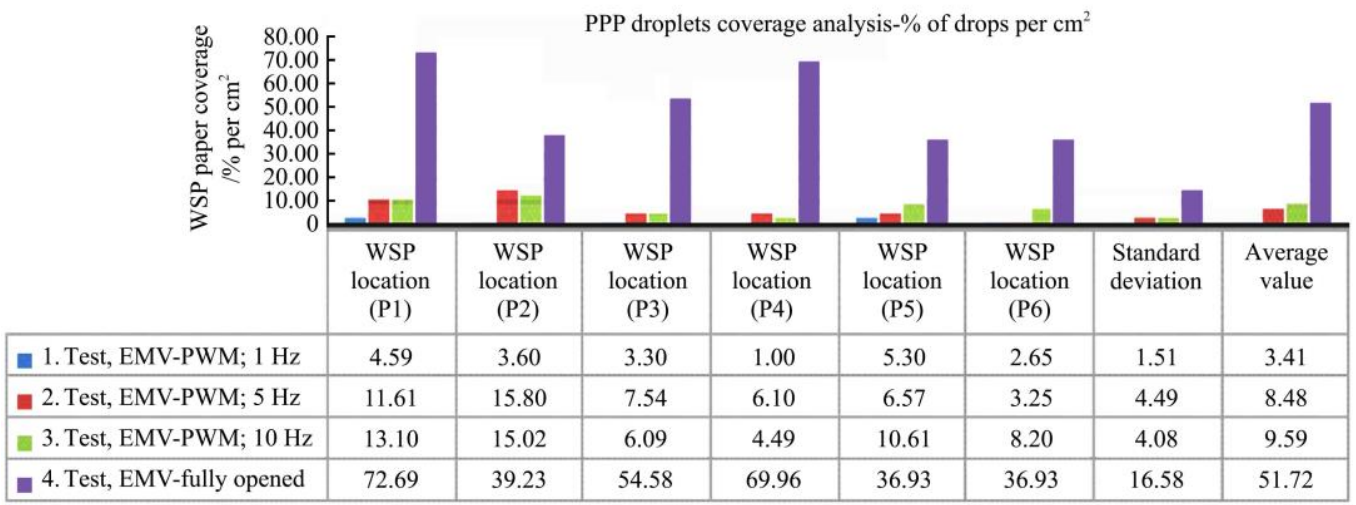

Figure 19 Coverage graph in \% for all four tests - at 1, 5, $10 \mathrm{~Hz}$ and fully open EMV

\section{Conclusions}

The decision-making model based on the fuzzy logic algorithm proved to be sufficiently for distributing the PPP in the real-time, with significant advantages over the conventional mode. The fuzzy logic algorithm allows the possibility of including personal knowledge about the problem and transferring it to the decision-making process, thus moving it closer to the human way of thinking. To evaluate the model, three fuzzy logic based PWM modules were compared to the conventional spraying mode. The $10 \mathrm{~Hz}$ PWM module resulted in the optimum number of droplets per $\mathrm{cm}^{2}$ and a small coverage variance between $4.49 \%$ and $15.02 \%$, 
still enough for adequate protection against disease and pests. In the case of the $1 \mathrm{~Hz}$ and $5 \mathrm{~Hz}$ PWM modes, the EMV reacted too slowly.

In the automated spraying mode $-10 \mathrm{~Hz}$ PWM 4.8 times less liquid was spent and achieving droplets coverage $(4.49 \%$ and $15.02 \%$ ), but still achieving the goal: efficient pest and disease protection. Further improvement of the decision-making model would mean including more parameters (varying the tractor speed, the speed and direction of the wind and varying air pressure) needed to define the opening/closing EMV time more accurately. This would lead to more input/output variables, along with additional membership functions and rules in the first stage; we could even introduce a lookup table to prepare the responses of the fuzzy logic algorithm based on different input combinations from different sensors in the second stage ${ }^{[28,29]}$. This would, of course, increase the number of rules, but only those influencing the PPP process. Naturally, better EMV with higher switching frequency would also contribute to a greater degree of system accuracy.

\section{Acknowledgments}

This article was partly created as a result of the applied EUREKA project (No. 3211-10-000040). The authors also acknowledge the Agricultural Institute of Slovenia for technical support in carrying out experiments and Professor dr. Michelle Gadpaille for help in editing the manuscript.

\section{[References]}

[1] Ladd T L, Reichard D L. Photoelectrically-operated intermittent sprayers for insecticidal control of horticultural pests. Journal Economic Entomology, 1980; 73: 525-528.

[2] Giles D K, Delwiche M J, Dodd R B. Sprayer control by sensing orchard crop characteristics: orchard architecture and spray liquid savings. Journal Agricultural Engineering Research, 1989; 43: 271-289.

[3] Balsari P, Tamagnone M. An ultrasonic airblast sprayer. AgEng 98 International Conference, EurAgEng Paper No. 98A-017, 1998; Oslo, Norway.

[4] Doruchowski G, Jaeken P, Holownicki R. Target detection as a tool of selective spray application on trees and weeds in orchards. SPIE Conference on Precision Agriculture and Biological Quality, Boston. Proc. SPIE 3543, 1998; pp.290-301.

[5] Meron M, Cohen S, Melman G. Tree shape and volume measurement by light interception and aerial photogrammetry. Transactions ASAE, 2000; 43(2): 475-481.

[6] Walklate P J, Cross J V, Richardson G M, Murray R A, Baker D E. Comparison of different spray volume deposition models using LIDAR measurements of apple orchards, Biosystems Engineering, 2002; 82(3): 253-267.

[7] Escolà A, Camp F, Solanelles F, Llorens J, Planas S, Rosell J R, et al. Variable dose rate sprayer prototype for dose adjustment in tree crops according to canopy characteristics measured with ultrasonic and laser LIDAR sensors, Proceedings ECPA-6th European Conference on Precision Agriculture, 2007; pp.563-571

[8] Solanelles F, Escolà A, Planas S, Rosell J R, Camp F, Gràcia F. An electronic control system for pesticide application proportional to the canopy width of tree crops. Biosystem Engineering, 2006; 95(4): 473-481.

[9] Escolà A, Planas S, Rosell J R, Pomar J, Camp F, Solanelles F, et al. Performance of an ultrasonic ranging sensor in apple tree canopies. Sensors, 2011; 11(3): 2459-2477.

[10] Jejcic V, Godesa T, Hocevar M, Sirok B, Malnersic A, Strancar A, et al. Design and testing of an ultrasound system for targeted spraying in orchards. Journal of Mechanical Engineering, 2011; 57(7-8): 587-598.

[11] Llorens J, Gil E, Llop J, Escolà A. Ultrasonic and LIDAR sensors for electronic canopy characterization in vineyards: Advances to improve pesticide application methods. Sensors, 2011; 11: 2177-2194.

[12] Sanz Cortiella R, Llorens Calveras J, Escolà A, Arnó Satorra J, Ribes Dasi M, Masip Vilalta J, et al. Innovative LIDAR 3D dynamic measurement system to estimate fruit-tree leaf area. Sensors, 2011; 11: 5769-5791.

[13] Stajnko D, Berk P, Lesnik M, Jejcic V, Lakota M, Strancar A, et al. Programmable ultrasonic sensing system for targeted spraying in orchards. Sensors, 2012; 11: 15500-15519.

[14] Chen Y, Zhu H, Ozkan H E. Development of a variable-rate sprayer with laser scanning sensor to synchronize spray outputs to tree structures. Transactions ASABE, 2012; 55(3): 773-781.

[15] Osterman A, Godesa T, Hocevar M, Sirok B, Stopar M. Real-time positioning algorithm for variable-geometry air-assisted orchard sprayer. Computers and Electronics in Agriculture, 2013; 98: 175-182.

[16] Escolà A, Rosell-Polo J R., Planas S, Gil E, Pomar J, Camp F, et al. Variable rate sprayer. Part 1: Orchard prototype: Design, implementation and validation. Computers and Electronics in Agriculture, 2013; 95: 122-135.

[17] Balsari P., Tamagnone M. An automatic spray control for airblast sprayers: first results. 1997, In: Precision Agriculture '97, Warwick, UK 619-626.

[18] Moltó E, Martin B, Gutiérrez A. Pesticide loss reduction by automatic adaptation of spraying on globular trees. Journal of Agricultural Engineering Research, 2001; 78: 35-41.

[19] Planas S, Rosell J R, Gil E, Val L, Escolà A, Solanelles F. Optimizing pesticide spray application in tree crops. In: 2006 ASABE Annual International Meeting, 2006; Portland, USA

[20] Walklate P J, Cross J V. Regulated dose adjustment of commercial orchard spraying products. Crop protection, 2013; 54: 65-73.

[21] Berk P, Stajnko D, Lakota M, Belsak A. Real time fuzzy logic system for continuous control solenoid valve in the process of applying the plant protection product. Agricultural Engineering, 2015; 15(1): 1-9.

[22] Giles K. Rate spray application without a change in droplet size. Australian Grain, 2009; 6: 38-39.

[23] Mamdani E H, Efstathiou J, Sugijama K. Developments in fuzzy logic control, Proceedings of 23rd conference on decision and control, Las Vegas, USA, 1984; pp.888-893.

[24] Liu F, Zhang J, Chen J. Modeling of flexible wheat straw by discrete element method and its parameter calibration. Int J Agric \& Biol Eng, 2018; 11(3): 42-46.

[25] Zimmerman H J. Fuzzy set theory and its applications. Kluwer-Nijhoff Publishing, Boston, USA, 1991

[26] Berk P, Rakun J, Lakota M, Muskinja N. The influence of distance ultrasonic density meassurements, In: Katalinic B. DAAAM International Scientific Book 2013, Vienna, 2013; pp.637-646.

[27] Water-sensitive paper for monitoring spray distributions. $\mathrm{CH}-4002$. Basle, Switzerland: Syngenta Crop Protection AG, 2002.

[28] Zhang X, Liu D, Fan C, Du J, Meng F, Fang J. A novel and smart automatic light-seeking flowerpot for monitoring flower growth environment. Int J Agric \& Biol Eng, 2018; 11(2): 184-189.

[29] Jantzen J. Tuning of fuzzy PID controllers. Technical Report, Dept. of Automation, Technical University of Denmark, 1999. 